\title{
Failure of a Natural Gas Transmission Pipeline-Material or Sabotage
}

\author{
Muhammad Mansoor ${ }^{1, *}$, Noveed Ejaz ${ }^{1}$, Amjad Ali ${ }^{1}$, Khalid Mehmood Ghauri ${ }^{2}$, Gul Hameed Awan ${ }^{3}$ \\ ${ }^{1}$ Department of Materials, Institute of Industrial Control Systems, Rawalpindi, Punjab province, Pakistan. \\ ${ }^{2}$ Department of Materials, University of Lahore, Lahore, Punjab province, Pakistan. \\ ${ }^{3}$ Department of Materials, University of Engineering \& Technology, Lahore, Punjab province, Pakistan.
}

How to cite this paper: Muhammad Mansoor, Noveed Ejaz, Amjad Ali, Khalid Mehmood Ghauri, Gul Hameed Awan. (2022) A

Class of Copulas Associated with Brownian Motion Processes and Their Maxima. OAJRC Material Science, 2(1), 1-11.

DOI: 10.26855/oajrcms.2022.02.001

Received: December 6, 2021

Accepted: January 2, 2022

Published: February 18, 2022

*Corresponding author: Muhammad Mansoor, Department of Materials, Institute of Industrial Control Systems, Rawalpindi, Punjab province, Pakistan.

Email: malik01677@yahoo.com

\begin{abstract}
A catastrophic failure of gas transmission line resulted in disruption of the gas supply to power generation plant. The pipe material was subjected to initial investigations including chemical analysis, hardness testing and tensile testing, which ruled out the failure due to the material degradation. Multiple, randomly oriented failure origins on outer surface of the pipe indicated some external cause(s) of the failure. Therefore, deposits and debris located at and around the fracture regions were carefully collected for detailed examination. The investigation findings were clearly indicating the intentional breach of pipe integrity. The major evidences included: i) presence of "explosive compound traces" as indicated by Fourier Transform Infrared spectrums of sand/deposits on the fracture origins; ii) the evidence of "Aluminum" on fracture surfaces; and iii) heavily deformed pipe walls and severely disintegrated fragments/debris having regions of localized melting/fusion. The usage of explosive was suspected to sabotage the pipeline operation.
\end{abstract}

Keywords

Pipeline Failure, Defragmented pipe, SEM, FTIR, Sabotage

\section{Background}

A gas transmission pipeline failed, passing through a dessert, causing an interruption in the gas supply to an associated power generation plant. The location of the failure was $5 \mathrm{~km}$ away from power generation plant. The failed pipe was in service since last three years and transmitting a mixture of gases (i.e., hydrocarbons, $\mathrm{H}_{2} \mathrm{~S}$, and $\mathrm{CO}_{2}$ etc.). An inhibitor had also been continuously injected with recommended dosage to protect internal corrosion. The material of the pipe was API 5L Grade X65 -a plain carbon steel [1]. The pipe material was intended to endure $800 \mathrm{ppm}$ of $\mathrm{H}_{2} \mathrm{~S}$ gas. The concentration of $\mathrm{H}_{2} \mathrm{~S}$ was around $15-40 \mathrm{ppm}$ in gas mixture. The composition of the gas mixture flowing into the pipe is given in Table 1 .

The outer diameter of the pipe was 26 inch $(660 \mathrm{~mm})$ with nominal wall thicknes $3 /$ sofnch $(9.5 \mathrm{~mm})$. Submerged arc welding technique had been employed to fabricate the pipe from the rolled sheet. The exterior surface of the pipe was coated with a $500 \mu \mathrm{m}$ thick layer of fusion-bonded epoxy (FBE) paint.

The failed pipeline was sectioned and repaired for successive pipeline operation, while the failed pipe section was sent to the present investigation laboratory for investigations. The main requirement of the investigation studies was to discern the failure cause(s), i.e., due to material, process or sabotage. 
Table 1. Composition of the process gas in the pipeline

\begin{tabular}{cccc}
\hline Gas Component & Mole \% & Gas Component & Mole \% \\
\hline Methane & $38-42$ & n-Pentane & $0.07-0.09$ \\
Ethane & $1.0-1.5$ & Hexane & $0.1-0.2$ \\
Propane & $0.30-0.50$ & Nitrogen & $19-21$ \\
Iso-Butane & $0.10-0.15$ & Carbon Dioxide & $35-37$ \\
n-Butane & $0.10-0.15$ & Hydrogen Sulfide (ppm) & $10-40$ \\
Iso-Pentane & $0.07-0.09$ & - & - \\
\hline
\end{tabular}

\section{Investigations}

Investigation comprised of visual examination, material analysis of the pipe material, wet chemical analysis of the surface deposit and Fourier transformed infrared (FTIR) spectroscopic analysis of the deposits found on and around the failure region. Additionally, microscopy and mechanical testing (i.e., hardness, tensile and impact testing) were carried out to validate the integrity of the pipe material.

\subsection{Visual Examination}

The failed pipe was sectioned within 3-feet from either side of the failure using flame-cutting technique and subjected to failure analysis to discern root cause(s). The visual examination was carried out using a low power magnifier and a stereo microscope.

The fractured region was encompassed by 3 to 4 feet length of the pipeline. The general features of failure indicate that the rupture comprised of randomly directed multiple fracture lines, which indicated a characteristic catastrophic failure that gave away some disintegrated fragments of the pipe. These disintegrated fragments were featured with localized melting, pierced-through holes with smeared metal at the edges, severe bending/folding and wall thinning. The fracture path did not follow the weld seam; instead, it was passing across the weld seam. The wall thickness was found reduced to ca. $8 \mathrm{~mm}$ in majority of the fracture surfaces (Figure 1a-1c).

The general appearance of the fracture region was identical except for two locations. These locations are shown schematically in Figure 2 and named as "LDP” and "LDI". At the location "LDP”, features of external impact were seen (Figure 2a \& $2 b)$. These impact features were incorporated with fusion, smearing, and severe penetration from external side. The region of damage was around $180 \mathrm{~mm}$ wide along the periphery of the pipe. An ingress pattern of fracture surface along with secondary cracks was seen at this location.

At the location "LDI", deep indents were observed. These indents were round or oval in shape and accompanied reduction in the wall thickness (Figure 2c \& 2b). The damaged region was $~ 535 \mathrm{~mm}$ wide along the periphery of the pipe.

Additionally, both internal and external surfaces of the failed pipe were examined thoroughly with the help of magnifier for any evidence of corrosion feature; no sign of corrosion initiation and/or growth were found.
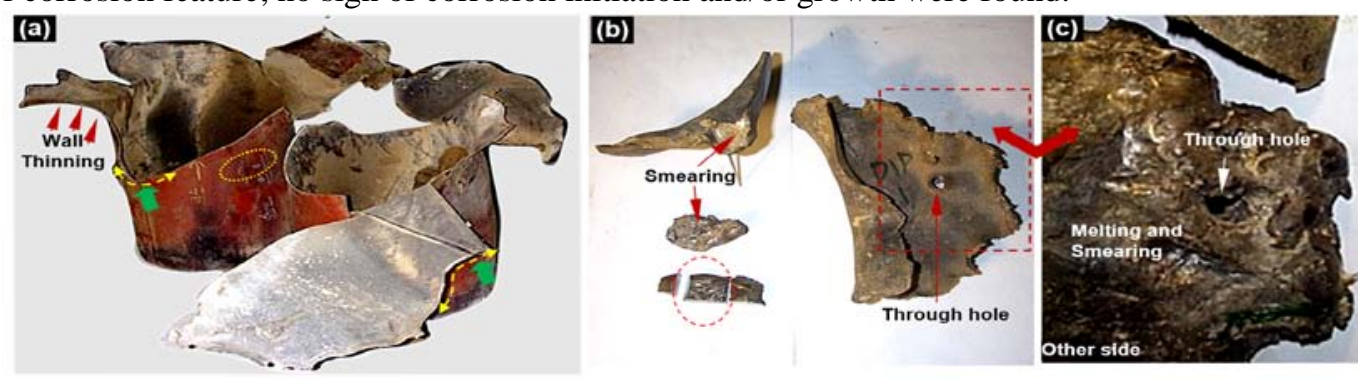

Figure 1. a) Fracture regions of the pipeline-fracture path crossed the weld seam (green arrows). A $20 \times 15$ in $^{2}$ piece from circled region was cut to prepare samples for mechanical testing, b) disintegrated fragments of the damaged pipe, c) magnified image of the boxed region in (b) showing melting and smearing features. 

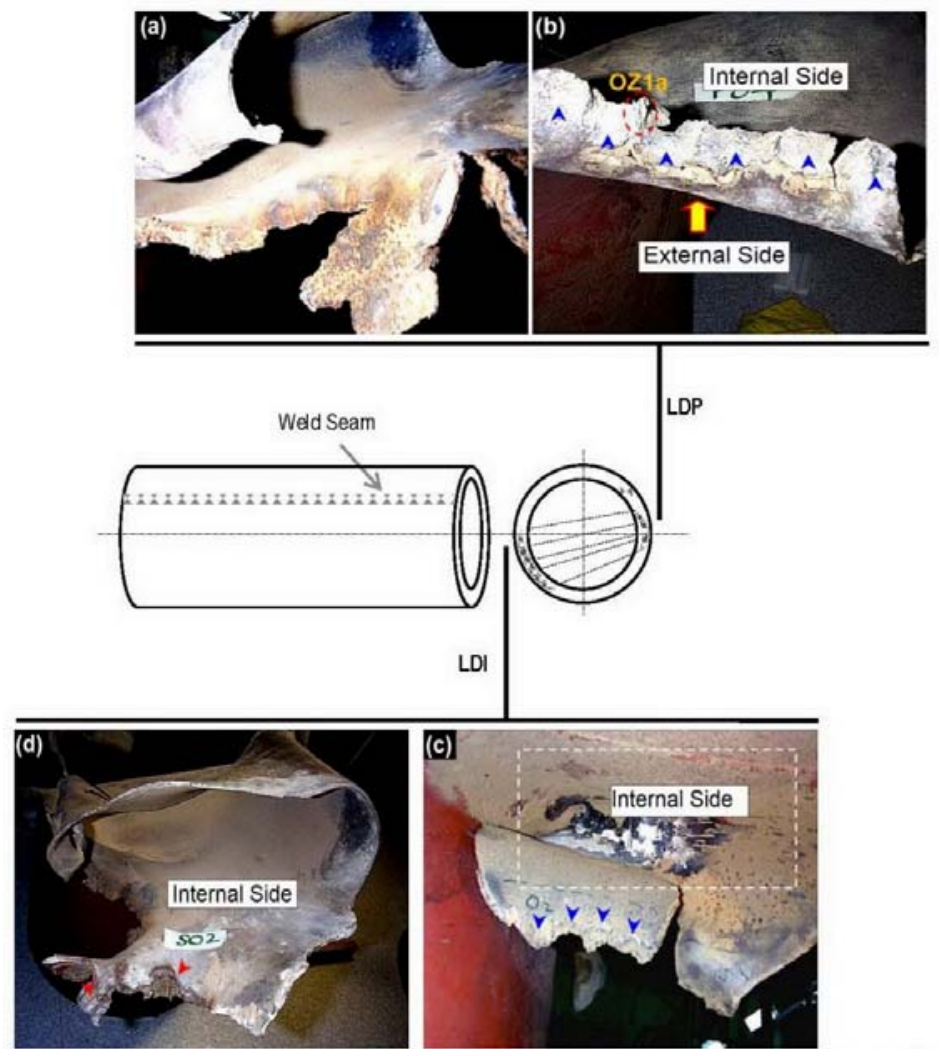

Figure 2. The schematic is showing the orientation of the two discernable fracture surfaces i.e., LDP (a and b) and LDI (c and d): a) Tearing of the pipe wall, b) features of external impact, smearing, and fusion (arrows); sample 'OZ1a' was collected from the encircled region, c) wall of the pipe is pressed outward due to severe impact (boxed region) and d) thinning of wall thickness at inner side (arrows).

\subsection{Sampling}

Specimens were taken from various locations of the failed pipe. Some specimens were taken from the outer surface of the pipe and from the fracture surface, i.e., LDP and LDI. The exact location/nomenclature of these specimens is given in Table 2. Besides these, a piece of $20 \times 15 \mathrm{in}^{2}$ was sectioned from the pipe lengths nearby fractured regions and samples were prepared for mechanical testing and optical microscopy. A schematic is presented in Figure 3 to facilitate the understanding of different specimens (deposits and debris) from various locations of the failure.

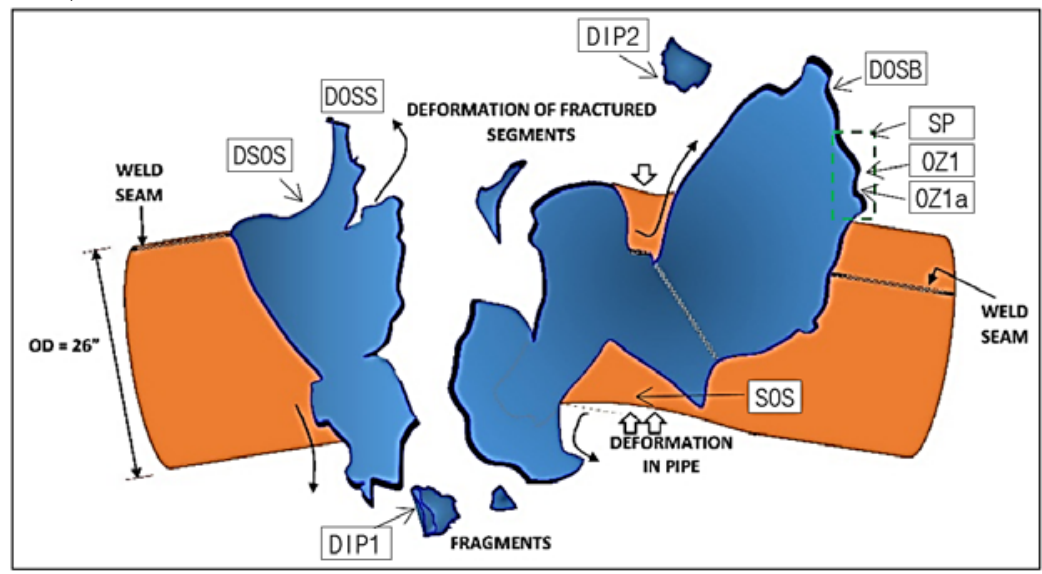

Figure 3. Schematic representation of the observed features of the failure along with the marking of the test specimens. 
Table 2. Nomenclature of the specimens (deposits and debris) collected from various locations as marked in Figure 3

\begin{tabular}{ccr}
\hline S. No. & Specimen ID & Description \\
\hline 1 & SOS & Scale/deposits collected from deformed region (near LPI) of the pipe. \\
2 & DOSS & Deposits/foreign particles collected from the outer surface where smearing was found around LPD location. \\
3 & DSOS & Deposits of sand collected from the outer surface where smearing was found around LPD location. \\
4 & DOSB & Black sand deposits collected from outer surface of the pipe. \\
5 & SP & Fand/deposits collected from fractured surface of pipe from LPD location. \\
6 & OZ1 & Small fragment cut from LDP region. \\
7 & OZ1a & Sand collected from the location of accident. \\
8 & SO & Sand collected from 30 feet away from the location of accident. \\
9 & SO-30 & Specimen having smearing features - disintegrated piece. \\
10 & DIP-1 & Specimen having fusion features - disintegrated piece. \\
\hline 11 & DIP-2 &
\end{tabular}

\subsection{Pipe Material Analysis}

The chemistry of the pipe material was determined using of emission spectrometer, energy dispersive spectrometer (EDS) equipped within scanning electron microscope (SEM) and combustion type carbon-sulfur (C/S) analyzer. The chemical composition is given in the Table 3. The material composition was comparable to the standard API 5L Grade X65 [1].

Table 3. Chemical composition of the pipe material

\begin{tabular}{cccc}
\hline \multirow{2}{*}{ Element } & \multicolumn{3}{c}{ Weight \% } \\
& Emission Spectrometer & EDS & Standard API 5L-X65 \\
\hline $\mathrm{Fe}$ & Balance & Balance & Balance \\
$\mathrm{C}$ & $0.24 \pm 0.04$ & $0.25 \pm 0.02^{*}$ & $0.23-0.28$ \\
$\mathrm{Mn}$ & $1.42 \pm 0.31$ & $1.33 \pm 0.42$ & $0.9-1.25$ \\
$\mathrm{Si}$ & $0.25 \pm 0.11$ & $0.38 \pm 0.2$ & $\leq 0.5$ \\
$\mathrm{~S}$ & 0.0008 & $0.0007^{*}$ & $\leq 0.05$ \\
$\mathrm{P}$ & 0.015 & $0.016^{*}$ & $\leq 0.04$ \\
$\mathrm{Cu}$ & $0.25 \pm 0.08$ & $0.31 \pm 0.07$ & - \\
\hline
\end{tabular}

*Analysis by C/S analyzer.

\subsection{Wet Analyses of the Deposits and Debris}

Inductive coupled plasma (ICP) and atomic absorption (AAS) studies were carried out for the analyses of SOS, DOSS, DSOS, DOSB, SO, SO-30 and SP specimens. The results are shown in Table 4. Besides the sand components like Ca, Mg, Si, $\mathrm{Na}$, etc., the DOSS and DSOS samples also indicated the presence of aluminum. The presence of aluminum at the location LPD made it an anomaly, as rest of the deposits did not show any such evidences. Therefore, it was suspected that in case of sabotage of the pipe, it could be the residual of liner material of some explosive [2]. However, no splinter or pieces of aluminum were recovered from the site of accident. 
Table 4. Trace analysis of samples by ICP and AAS

\begin{tabular}{cccccccc}
\hline \multirow{2}{*}{ Elements } & \multicolumn{7}{c}{ Concentration in ppm } \\
& SOS & DOSS & DSOS & DOSB & SO & SO-30 & SP \\
\hline $\mathrm{Al}$ & - & 4.7 & 3.2 & - & - & - & - \\
$\mathrm{Mg}$ & 4.89 & 1.27 & 15.73 & 3.12 & 49.1 & 15.9 & 3.27 \\
$\mathrm{Ca}$ & 27.2 & 10.04 & 87.6 & 15.9 & 289.5 & 107.7 & 43.9 \\
$\mathrm{Si}$ & 1.66 & 0.49 & 4.12 & 0.69 & 13.6 & 6.5 & 4.64 \\
$\mathrm{~Pb}$ & - & - & - & - & - & - & - \\
$\mathrm{Zn}$ & - & - & 0.57 & - & 0.93 & - & - \\
$\mathrm{Na}$ & 1550 & 238 & 5080 & 500 & 15242 & 3703 & 544 \\
$\mathrm{~K}$ & 381 & 88 & 444 & 175 & 3100 & 194 & 333 \\
$\mathrm{Li}$ & - & - & 0.6 & 0.3 & 5.0 & 3.5 & 3.1 \\
$\mathrm{Ba}$ & - & - & - & - & - & - & - \\
$\mathrm{Sb}$ & - & - & - & 11 & 15.0 & 32.0 & - \\
\hline
\end{tabular}

\subsection{FTIR Analysis}

The infrared (IR) spectroscopy is very helpful tool to identify the explosive compounds even after explosion and/or present in trace amounts. It is said by forensic experts that the "Fourier Transform Infrared Spectroscopy (FTIR) is a workhorse instrument in forensic explosives analysis” [3-6]. The specimens for FTIR analysis were prepared in accordance with standard procedures and as follows: potassium bromide $(\mathrm{KBr})$ pallets, accompanying deposits found on the samples, were prepared. Mixing and dispersion of the specimens in $\mathrm{KBr}$ powder was carried out by grinding, then the mixture was compacted to pellets using metallic die and pressing machine. Typically, $1 \mathrm{mg}$ of the specimen was ground in $250 \mathrm{mg}$ of $\mathrm{KBr}$ using a planetary ball mill for 30 minutes. Sufficient grinding and thorough mixing ensure the reduced distortion of the spectrum bands due to scattering effects [7].

All the specimens mentioned in Table 2 were subjected to the FTIR spectroscopy in the range from 500 to $4,000 \mathrm{~cm}^{-1}$ and compared with various types of commonly used explosives i.e., C-4, ETN, HMX, PETN, TATP and RDX. While comparison, only three specimens were indicative of the presence of some explosive residuals. These specimens were SOS (from LPI region), DSOS (from LPD region) and OZ1a (segments of LPD region). The superimposed FTIR scans are shown in Figure 4 along with a peak identifier spectrum of cyclo-trimethylene-trinitramine (an explosive material), which was quoted by some other researchers independently [8].

The FTIR spectra of unexploded and exploded cyclo-trimethylene-trinitramine also known as "Royal Demolition Explosive" (RDX) are comparable. Therefore, the spectrum of OZ1a specimen was substantially analogous with the peaks suggested for RDX exploded spectrum by Yang et al. [8]. However, some peaks intensities were found different from the cited reference, which could be due to the limited amount of available traces of the explosive on and around the fracture region. Rest of the two specimens i.e., SOS and DSOS exhibited weak peaks with feeble intensities besides absence of some peaks. Though not decisive but it could be attributed to the presence of exploded explosive as an empirical evidence.

The RDX is a synthetic material and has the molecular formula $\mathrm{C}_{3} \mathrm{H}_{6} \mathrm{~N}_{6} \mathrm{O}_{6}$; the structure is shown in the in-set of Figure 4. The oxygen atoms of nitro functional group $\left(-\mathrm{NO}_{2}\right)$ could be considered as comparable due to resonance i.e., ${ }^{+} \mathrm{O}-\mathrm{N}=\mathrm{O}$ and $\mathrm{O}=\mathrm{N}-\mathrm{O}^{+}$. The $-\mathrm{NO}_{2}$ group shows three degree of freedoms with respect to the bond vibrations: i) strong reflections in the region 1,530 to $1,560 \mathrm{~cm}^{-1}$; ii) moderate reflections in 1,210 to $1,360 \mathrm{~cm}^{-1}$ range; and iii) weak reflections in the region 840 to $930 \mathrm{~cm}^{-1}$ representing asymmetric, symmetric and bending frequencies, respectively [4, 9]. In experimental spectra of the present work, these reflections appeared at 1,541, 1,260 and $854 \mathrm{~cm}^{-1}$. 


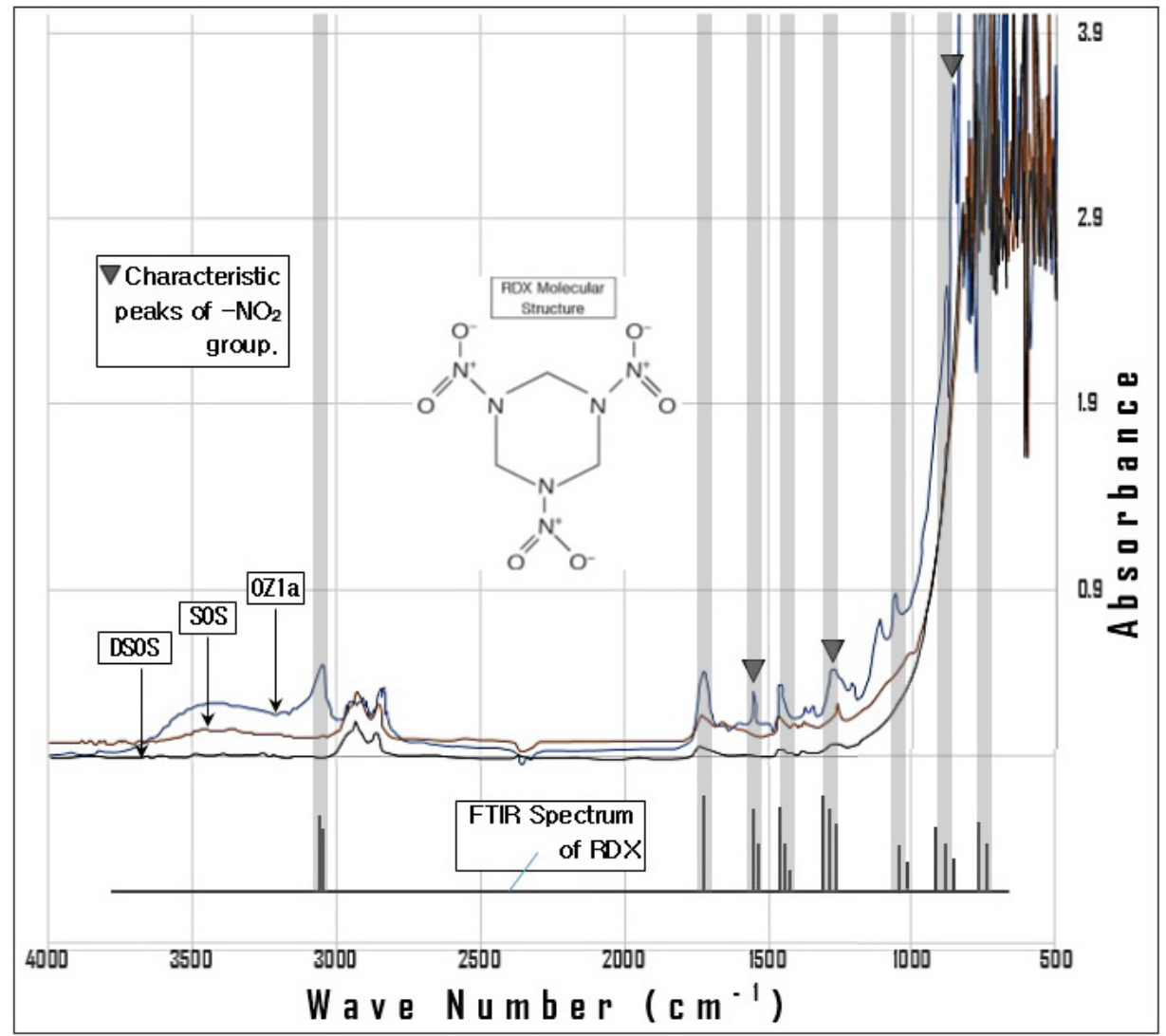

Figure 4. Superimposed FTIR spectra of DSOS, SOS and OZ1a specimens indicating $-\mathrm{NO}_{2}$ peaks. The referred FTIR spectrum of RDX is mentioned at the bottom, showing its compliance with the experimental results. Inset is showing molecular structure of RDX.

\subsection{Microscopy}

Specimens were prepared for microscopic observation using standard metallographic techniques. The specimens for general microstructure of the pipe material was etched using Nital (5\% Nitric acid in ethanol) to reveal the microstructural details. The microstructure revealed equi-axed grains of ferrite with pearlite colonies both in longitudinal and transverse sections of the pipe (Fig. 5a). The size of ferrite varied from 5-25 $\mu \mathrm{m}$. However, no defect or features such as stress corrosion cracking [10], hydrogen fissures [11], and spheroidization [12] were observed.

The specimens taken from the fracture surface at OZ-1, and fracture surface of the deformed fragment at DP-1 and melt-deposition features at DP-2 fragment were studied using scanning electron microscope (SEM). Energy dispersive spectrometer with micro-probe was used for qualitative analysis of different type of deposits on the fracture surfaces.

In specimen OZ-1, the general fracture morphology appeared to be dimple rupture, which was a clear indicative of ductile fracture. The size and shape of the dimples were very small fracture, which specified a fast-moving crack of catastrophic nature i.e., overload [13]. The features are shown in Figure-5b, where the inset is a high magnification (5000x) image, showing nature of the dimples.

The fracture surface of the deformed segment (DP-1) appeared to be largely smeared (Figure-5c). The smearing marks were uni-directional; indicating the direction of fracture features happened during the failure. At some locations, clusters of particles were also seen. The qualitative analysis of these clusters appeared to be rich in $\mathrm{Al}, \mathrm{Si}, \mathrm{Ca}$ and $\mathrm{Mg}$ in the descending order. Similarly, point analysis of different regions of the fractured surface confirmed the presence of these elements with Al contents at the first or second place.

A quite bizarre feature of metallic aluminum deposits was seen on the DP-2 fragment. These deposits were present in the 
form of splashes on the fracture surface of the segment. The morphology of the splashes was like dendrites (Figure 5d), which suggested that the splashes were thin films of the solidified molten metal [14]. Such deposits were found only one location (DP-2), despite of thorough search of the rest of the failure regions.
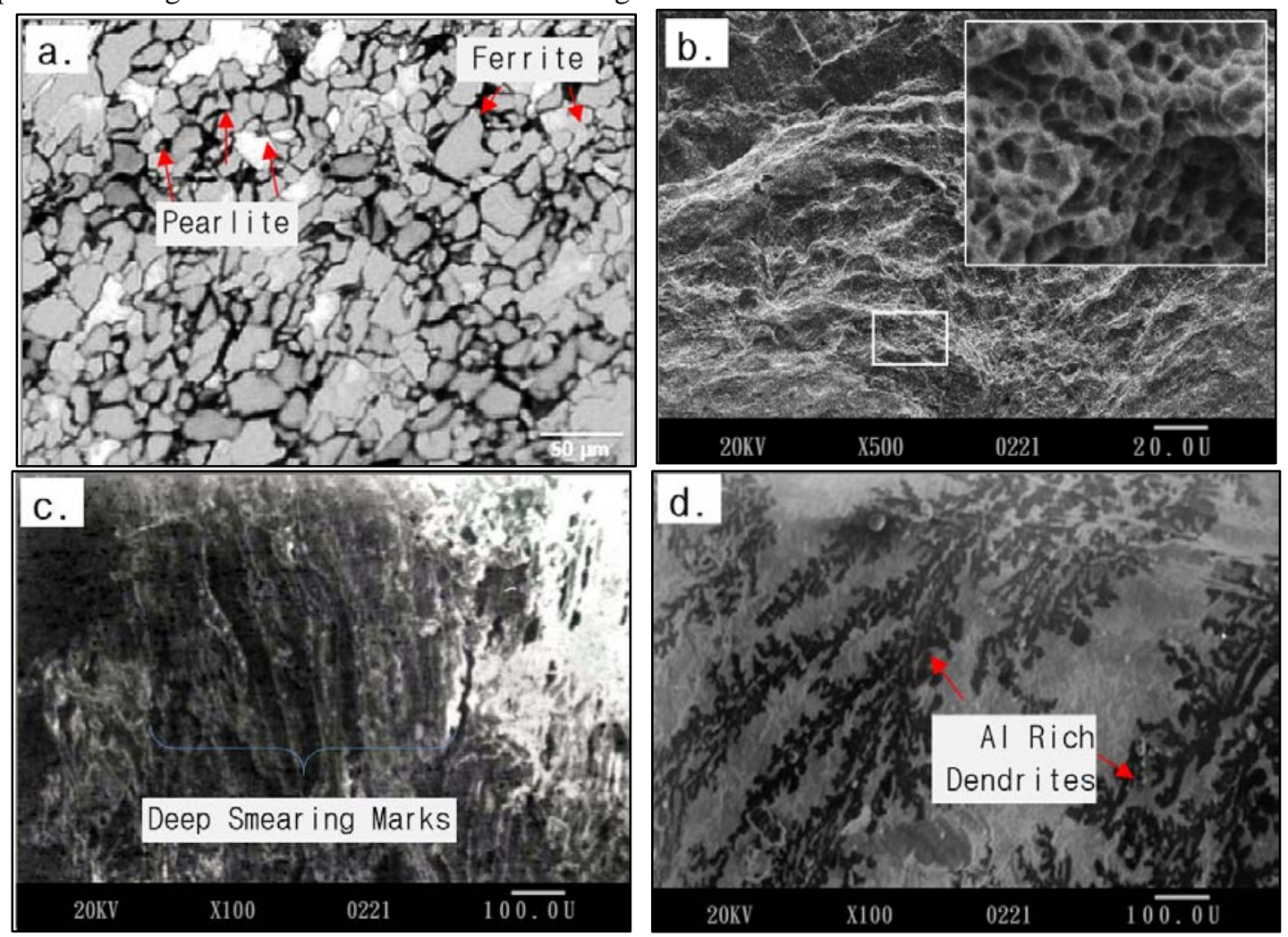

Figure 5. Micrographs of various specimens revealing. a). Optical micrograph of the general structure showing pearlite colonies embedded in ferritic matrix, b). Fracture surface at OZ-1 revealing fine dimples of overload nature, c). Metal smearing on the fracture surface sectioned from DP-1 region, and d). Micrograph showing aluminum dendrites on the outer surface of disintegrated fragment DP-2.

\subsection{Mechanical Testing}

Material integrity was validated by confirmation of the mechanical properties with the standard API 5L grade X65 specifications. The hardness of the pipe material was tested (longitudinal and transverse directions) with the help of Vickers hardness machine in accordance to ASTM standard [15]. The resultant hardness HV number is the expression derived from the applied force and surface area of the indent made by the diamond pyramid using equation-1:

$$
H V=2 P \sin \left(\frac{\alpha}{2}\right) / \mathrm{d}^{2}
$$

where:

$\mathrm{P}=$ force, kgf,

$\mathrm{d}=$ mean diagonal of impression, $\mathrm{mm}$, and

$\mathrm{a}=$ face angle of diamond $=136^{\circ}$.

At least five indents were taken on the surface of each specimen and average hardness values are determined with standard deviation.

Standard tension test samples i.e., round dog-bone shape, were prepared in longitudinal and transverse directions as per ASTM standard [16]. Tensile testing was carried out using INSTRON ${ }^{\top M}$ universal testing machine at a constant strain rate of $0.5 \mathrm{~mm} / \mathrm{min}$. three specimens were tested for average mechanical properties of the pipe material. 
Similarly, impact testing was carried out according to the specification of ASTM standard [17]. A Charpy impact-testing machine was used to determine the impact strength of the pipe material in both longitudinal and transverse direction of the pipe.

The results of mechanical testing are given in Table 5, along with where the standard mechanical properties of API 5L Grade X65.

Table 5. Mechanical properties of the pipe material

\begin{tabular}{ccccc}
\hline S. No. & Property & Longitudinal direction & Transverse direction & API 5L Grade X65 [1] \\
\hline 1 & Ultimate Tensile Strength ksi) & $80-81$ & $80-81$ & $>70$ \\
2 & Yield strength (ksi) & $77-78$ & $74-76$ & $>65$ \\
3 & Elongation (\%) & $22-25$ & $22-23$ & $>20$ \\
4 & Impact Energy (J) & $>275^{*}$ & $>274^{*}$ & $>250$ \\
5 & Hardness (Hv) & $182 \pm 3$ & $179 \pm 3$ & $165-185$ \\
\hline
\end{tabular}

*The samples remained un-broken.

\section{Discussion}

During macroscopic examination, it was observed that some sort of penetration from external side of the pipe occurred. The penetration caused smearing and severe deformation at the outer surface of the pipe (Figure 1). At LDP location (as marked in Figure 2a \& 2b), features of external impact, smearing, and fused metal along with tearing of the pipe wall were present. At the fracture surface of DP-2 (Figure-2b), presence of molten aluminum was confirmed by EDS. Contrary to LDP location, internal impact features were seen at LDI position (Figure 2c \& 2d). At this location, thinning along with severe plastic deformation of the pipe wall was observed.

The observations were mapped on the periphery of the pipe for confirmation of any sequential damages (Figure 6). Two locations of the fracture surfaces of the entire failed region were distinctly identified by their features i.e., LPD and LPI as marked in Figure 6. These locations were almost opposite to each other.

At LPD location, some penetration/ingress type of fracture features was observed. These penetrations features were coarse in size, while having secondary cracks (Figure 6a). Additionally, at outer surface of the pipe external impact was the dominating feature accompanying smearing and localized deposits of molten aluminum metal. The molten metal appeared to be the splashed dendrites during SEM study (Figure 6b). These features were entirely unexpected under usual failure circumstances; hence, a wet analysis and FTIR were carried out on the deposits collected from the fracture surface and other corresponding regions i.e., from LPI region (SOS), from LPD region (DSOS) and segments of LPD region (OZ1a). The FTIR investigations indicated the presence of RDX traces on the fracture surface at this location (OZ1a), however outer and inner surfaces, which were bit away from it, did not show such evidences (Figure 6c). These features made the location LPD as primary fracture initiation point of the failure i.e., origin of the fracture.

At LPI location, a continuation of LPD devastation was observed, where the features of fracture surface depicted the penetration or fracture initiation from the inner side of the pipe (Figure 6d). It could be inferred that the debris and fragments from location LPD struck to the LPI location causing the fracture at this location from inner side. Moreover, the thinning of the pipe walls (Figure 6e) showed the overloading of the area at larger scale than LPD. The fractographic features of the location were overload type (Figure 6f).

The smearing of metal from outer side towards the inner side at different locations of the pipe along with inward indentation and folding indicated that the origin of the failure could have been on the outer side of the pipe. The features on the other way, rule out the possibility of over-pressure bursting. The over-pressure cylindrical components are generally led to leaks coupled with expansion in the pipe diameter [18], which was also not present in this case.

The microstructural examination, fractographic evaluation and mechanical testing gave no sign of material degradation such 
as, pitting, hydrogen blistering and sulfide stress cracking, etc. Moreover, the fracture path was passing across weld seam instead of moving along it. All these evaluations validate the soundness of the material i.e., material, welding or processing were not accountable for the failure.
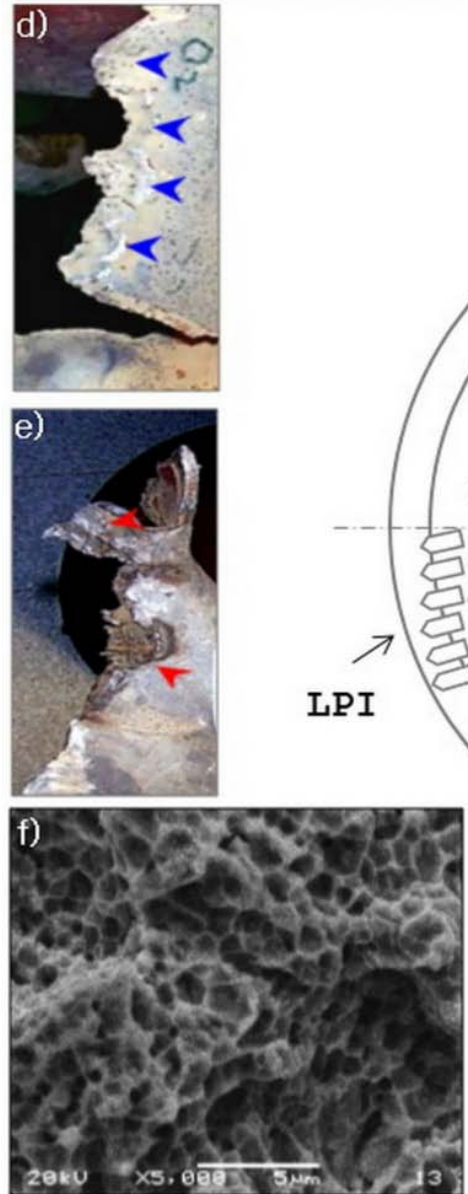

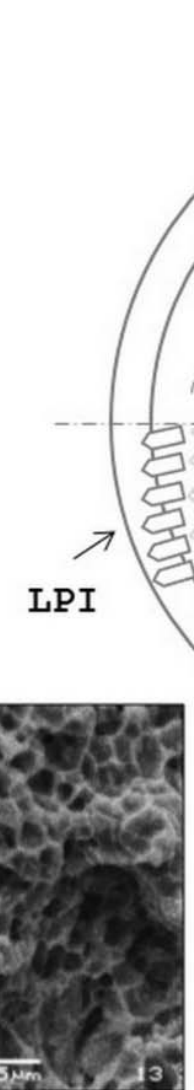

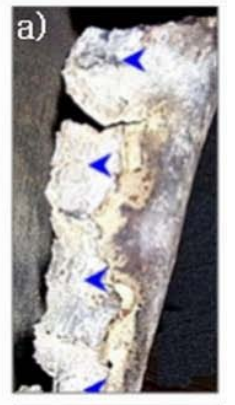

LPD
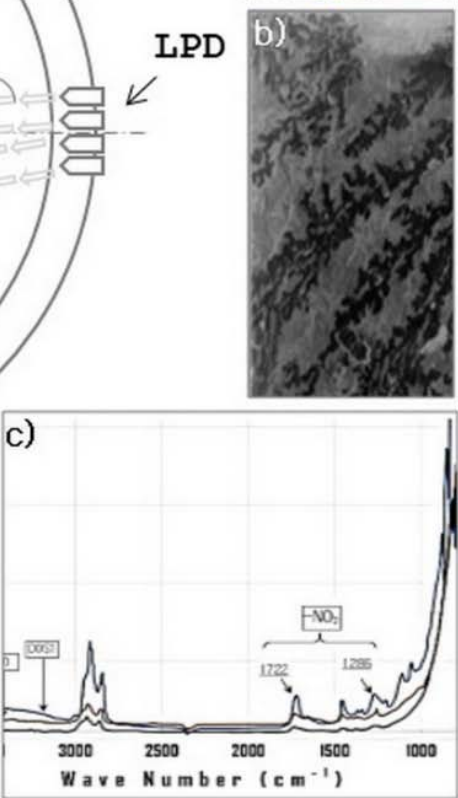

Figure 6. Schematic representation of the evidences found on locations LPD and LPI:

a) Penetration from outer surface of the pipe, b) Presence of Al dendrites and c) FTIR spectra showing $-\mathrm{NO}_{2}$ peaks, d) Penetration from inside of the pipe wall, e) Thinning of the pipe wall from inner side, and f) Overload fracture features.

\subsection{Sequence of the Failure}

A probable sequence of failure, deduced from the preceding findings and discussion, is represented schematically in Figure-7. It would be prudent to understand the structure and working principle rocket propelled grenade (RPG-7) to follow the probable failure sequence. An RPG-7 rocket comprises two major parts: grenade and rocket. The grenade has nose cap assembly, followed by warhead assembly comprising a copper or aluminum liner and explosive charge. Rest of the assembly comprises rocket motor, which propagates the grenade to the target (Figure 7a). When the propelled RGP-7 approaches to the target (Figure 7b), the nose assembly ignites the explosive charge, which consequently pushes the metallic liner into the target and pierce through it (Figure 7c). The pierced hole provides a narrow passage for the pressurized gases inside the grenade to disintegrate the target catastrophically (Figure 7d) [19].

Based on the findings during investigation, the sequence of the failure could be as follows: at location LDP, penetration from the outer side was observed along with aluminum dendrites and presence of explosive material (Figure 6a to 6c), which could be the consequence of the first strike of an RPG rocket (Figure 7c). At location LPI, inside penetration, wall thinning and overload features (Figure 6d to 6f) were present, which represent the subsequent damage made by the rocket as demonstrated 
in Figure 7d.
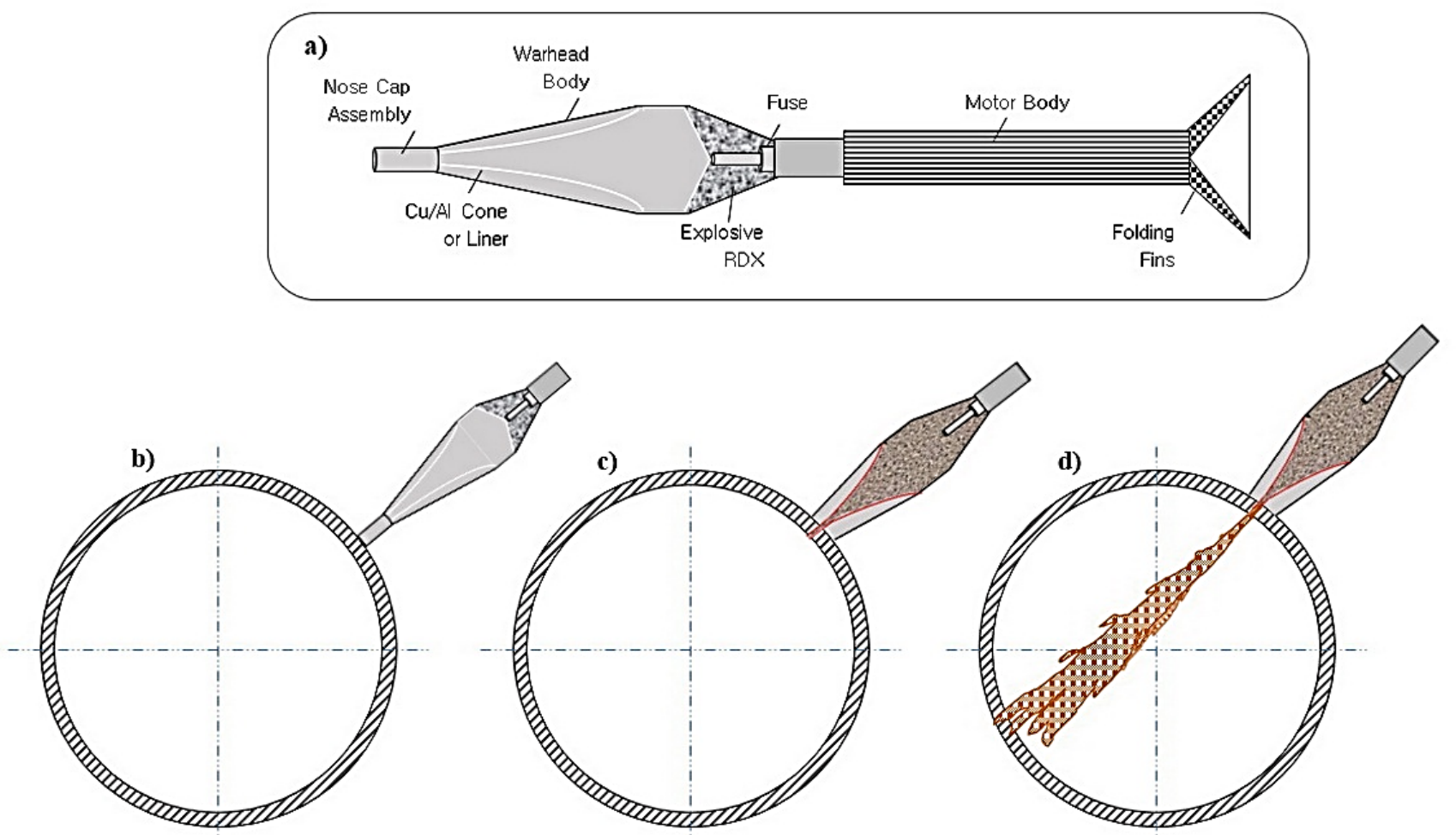

Figure 7. Schematic presentation of the sequence of the failure. a) layout of the RPG rocket, b) rocket approaching to the target, c) first damage and piercing and d) subsequent damage.

\section{Conclusion}

The severely deformed fragmentation of the pipe, the detection of explosive compound during FTIR spectra of sand/deposits and the revealing of aluminum on the disintegrated fragments, fracture surfaces and deposits on the pipe left no reservation to suspect the usage of high explosives to sabotage the pipe.

\section{References}

[1] ASM Metals Handbook. (1992). Properties and Selection: Irons, Steels, and High-Performance Alloys, Vol-1, ASM publications, Metals Park, Ohio, USA, 1992, 877-878.

[2] www.uxoinfo.com/blogcfc/client/includes/uxopage/mulvaney_details.cfm?Ord_ld=R6, visited on 26 November 2020.

[3] M. Marshall, J. C. Oxley. Aspects of explosive detection, Elsevier, Amsterdam, Netherlands. DOI: 10.1021/ac60160a013.

[4] M. Lopez, L. Carmen, G. Ruiz. (2014). Infrared and Raman spectroscopy techniques applied to identification of explosives, TaAC Trends in Analytical Chemistry, 54, 36-44.

[5] D. J. Klapec, G. Czarnopys. (2016). Analysis and detection of explosives and explosives residues review: 2013 to 2016, in: 18th Interpol International Forensic Science Managers Symposium, Lyon 11th-13th October 2016, 2016, pp. 194-261.

[6] D. J. Klapec, G. Czarnopys, J. Pannuto. Interpol review of detection and characterization of explosives and explosives residues 2016-2019. Forensic Science International: Synergy, Available online 17 June 2020.

[7] ASM Metals Handbook, Volume-10, Materials Characterization, $5^{\text {th }}$ Edition, 1998, Metals Park Ohio, pp. $244-245$.

[8] C. S. C. Yang, B. R. Williams, A. Tripathi, M. S. Hulet, S. Melissa, C. Alen, J. A. Dominico, A. Joseph, M. Joseph, R. W. Miles, A. W. Fountain. (2014). Special characterization of RDX, ETN, PENT, TATP, HMTD, HMX, and C-4 in the mid-infrared region, Report No: ECBC-TR-1243, Battelle Eastern Science \& Technology Center, Department of Homeland Security, 245 Murray Lane SW, Washington DC, 2014. 
[9] S. P. Sherma, S. C. Lahiri. (2005). Characterization and identification of explosives and explosive residues using GC-MS, and FRIR microscope and HPTLC. Journal of Energetic Materials, 23, 4, 239-264.

[10] C. R. Walker, K. K. Starr. (1989). Failure Analysis Handbook, Pratt \& Whitney, West Palm Beach, FL, 1989, $46-50$.

[11] V. Ramachandran, A. C. Raghuram, R. V. Krishnan, and S. K. Bhaumik. (2005). Failure Analysis of Engineering Structures Methodology and Case Histories, ASM International, Metals Park, Ohio, 2005, 11-29.

[12] M. Mansoor, N. Ejaz. (2009). Prediction of in-service microstructural degradation of A106 steel using eddy current technique. Materials Characterization, 60, 1591-1596.

[13] ASM Metals Handbook, Fractography, Vol-12, ASM publications, Metals Park, Ohio, USA, 1992 34-40.

[14] Modern Physical Metallurgy and Materials Engineering, R. E. Smallman, R. J. Bishop, Sixth Edition, Butterworth-Heinemann Publishers, Oxford, 1999, 42-44.

[15] ASTM Standard Designation: E 92-82, Standard test method for Vickers hardness of metallic materials, 2003. ASTM International, 100 Barr Harbor Drive, PO Box C700, West Conshohocken, PA 19428-2959, United States.

[16] ASTM Standard Designation: E 8-04, Standard test methods for tension testing of metallic materials, 2003, ASTM International, 100 Barr Harbor Drive, PO Box C700, West Conshohocken, PA 19428-2959, United States.

[17] ASTM Standard Designation: E 23-2a, Standard test methods for notched bar impact testing of metallic materials, 1999, ASTM International, 100 Barr Harbor Drive, PO Box C700, West Conshohocken, PA 19428-2959, United States.

[18] M. Mansoor, A. Tauqir. (2008). Failure of heat exchanger tubes due to localized scaling and microstructural transformation. Journal of Failure Analysis and Prevention, 8, 434-440.

[19] http://science.howstuffworks.com/rpg.htm visited on 14 December 2020. 